\title{
Review
}

\section{Supporting Perinatal Mental Health and Wellbeing during COVID-19}

\author{
Laura Bridle ${ }^{1, *(1)}$, Laura Walton ${ }^{2}$, Tessa van der Vord ${ }^{3}$, Olawunmi Adebayo ${ }^{4}$, Suzy Hall ${ }^{5}$, Emma Finlayson ${ }^{1}$, \\ Abigail Easter ${ }^{6}$ and Sergio A. Silverio ${ }^{6}$ (D)
}

1 Women's Services, St. Thomas' Hospital, Guy's and St. Thomas' NHS Foundation Trust, London SE1 7EH, UK; Emma.Finlayson@gstt.nhs.uk

2 Women's and Children's Division, Princess Royal University Hospital, King's College Hospital NHS Foundation Trust, London BR6 8ND, UK; L.Walton1@nhs.net

3 Women's Health Services, Chelsea and Westminster Hospital, Chelsea and Westminster NHS Foundation Trust, London SW10 9NH, UK; t.vandervord@nhs.net

4 Maternity Services, Watford General Hospital, West Hertfordshire Hospitals NHS Trust, Watford WD18 0HB, UK; Olawunmi.Adebayo@nhs.net

5 Maternity Services, University Hospital Lewisham, Lewisham and Greenwich NHS Trust, London SE13 6LH, UK; Suzy.Hall@nhs.net

6 Department of Women \& Children's Health, School of Life Course \& Population Sciences, King's College London, London WC2R 2LS, UK; Abigail.Easter@kcl.ac.uk (A.E.);

Sergio.Silverio@kcl.ac.uk (S.A.S.)

* Correspondence: Laura.Bridle@gstt.nhs.uk

Citation: Bridle, L.; Walton, L.; van der Vord, T.; Adebayo, O.; Hall, S.; Finlayson, E.; Easter, A.; Silverio, S.A. Supporting Perinatal Mental Health and Wellbeing during COVID-19. Int. J. Environ. Res. Public Health 2022, 19, 1777. https://doi.org/10.3390/ ijerph19031777

Academic Editor: Andrew Mayers

Received: 30 December 2021

Accepted: 28 January 2022

Published: 4 February 2022

Publisher's Note: MDPI stays neutral with regard to jurisdictional claims in published maps and institutional affiliations.

Copyright: (C) 2022 by the authors. Licensee MDPI, Basel, Switzerland. This article is an open access article distributed under the terms and conditions of the Creative Commons Attribution (CC BY) license (https:// creativecommons.org/licenses/by/ $4.0 /)$.

\begin{abstract}
Mental health is especially important as women transition into parenthood. The COVID19 pandemic has necessitated the rapid reconfiguration of maternity services, including perinatal mental healthcare, as offered by Specialist Perinatal Mental Health Midwives, in NHS Trusts in the United Kingdom. This article represents work undertaken in rapid response to the COVID-19 pandemic and aims to document the findings from March 2020 up until May 2021 in literature published on perinatal mental health through the pandemic, as well as to engage in a knowledge mapping exercise across five NHS Trusts in London. In this research, we utilised a critical review methodology which purposefully selects and synthesises materials after extensive literature searching to provide a broad and informed narrative around an issue. For our knowledge mapping exercise, we utilised an inclusive stance to gather, pool, and synthesise data from five NHS Trusts regarding the provisions and reconfigurations of their perinatal mental health services, creating a comparable and translatable snapshot in time. Our rapid, critical review highlighted two themes: 'Increased Perinatal Distress' and 'Inaccessible Services and Support'. Our knowledge mapping exercise produced four themes: 'Retention of Existing Service Provision'; 'Additional Services Provided'; 'Reconfiguration of Service Provision'; 'Additional Provision to Support Staff Wellbeing'. We conclude by offering best practice guidance in order to provide shared learning to aid the transition through para-pandemic circumstances to service delivery in a post-pandemic 'new normal'.
\end{abstract}

Keywords: COVID-19; perinatal mental health; midwives; women's health; pregnancy; childbirth; postpartum

\section{Introduction}

Mental ill health can affect up to $20 \%$ of women at any time between pregnancy and 12 months post birth [1], which is referred to as the perinatal period. This ranges from mild to severe and can include a variety of illness, such as depression, bipolar disorder, anxiety disorders, and postpartum psychosis [2]. Perinatal mental illness is more common in women from Minority Ethnic groups [3], and a study conducted in South London found a prevalence of mental ill health of up to $27 \%$ in women pre-COVID-19 [4]. Since these statistics represent those women who receive formal diagnoses, it is likely that the prevalence of mental ill health in the perinatal population is much higher, with many 
women going undiagnosed and without treatment or support. Mental ill health in the perinatal period not only has devastating effects on a woman at the time they transition to becoming a mother, but also affects those around them, including their children, partners, family, and friends, whilst also posing a considerable financial burden to health and social care services [5]. The area of perinatal mental health has become a major focus of interest in recent times, with ongoing investment in new specialist mental health services [5].

The SARS-CoV-2 (coronavirus) or COVID-19 pandemic has brought about an unprecedented threat to the health of the population, as well as a significant change to daily life. Governments across the world have imposed stay-at-home orders (or 'lockdowns') and introduced physical distancing and quarantine measures in an attempt to reduce the spread of the virus and ease the burden on hospitals and healthcare systems, which have experienced and continue to experience record high numbers of patients requiring in-patient intensive care [6,7]. Whilst maternity services in the United Kingdom have continued to function, the capacity at which they are delivering care has been significantly reduced, with the almost total cessation of continuity of care and home-birthing, reduced provision of face-to-face antenatal and postnatal care, and limits on birth partners during labour [8]. In the early stages of the pandemic, the Royal College of Obstetricians and Gynaecologists recommended that pregnant women should 'shield' — that is, remain at home and under no circumstances leave unless attending a maternity care appointment, seeking urgent medical care, or attending hospital to give birth. This was later revoked, though lately there has been renewed concern that women in their third trimester may experience worse outcomes if they contract COVID-19 [9]

With the worry people have experienced about becoming ill and possibly dying from COVID-19 as well as the restrictions placed on human life, it is no wonder that "fear from the virus is spreading even faster than the virus itself" [10]; p. 129). For perinatal women, the psychological distress associated with COVID-19 is expected to pose "unprecedented challenges that can significantly impact on women's mental health" [11]; p. 310).

In 2018, the Royal College of Midwives (RCM) [12] released a document entitled "SPECIALIST MENTAL HEALTH MIDWIVES: What they do and why they matter". This document highlights the role perinatal mental health midwives play in supporting mental health in pregnancy, not just for women and families, but also for the whole multidisciplinary team. Midwives hold the unique position of sharing information on an infant's health right from the beginning of a pregnancy with the families they care for. This is an area which is sometimes forgotten in maternity, and it is crucial midwives start the conversation as early as possible.

Prior to the pandemic, perinatal mental health midwives based in London started a Pan-London Perinatal Mental Health Midwives Forum (L.B., L.W., T.v.d.V., O.A., and S.H.), supported by NHS England. Meetings were held quarterly to compare how roles were utilised, and members of the forum also acted to support one another. This helped to map out roles in terms of what each midwife was doing and whether there was uniformity in how they all worked-i.e., highlighting which Trusts were doing certain things, noting any inconsistencies and similarities, and establishing a functional network to link perinatal mental health midwives across London with those in bordering counties. This group has now grown to over 129 midwives throughout the UK and Ireland, offering a wonderful network of support during these unprecedented times. We hope that by sharing some of the ways we have changed the way we have supported women, we can help you and your service think of alternative ways to support women and families during COVID-19 and the subsequent years, which will undoubtedly be affected by this pandemic [10].

Whilst many women will experience perinatal mental health issues, the increased pressure of COVID-19 on both the public and healthcare services has meant that, understandably, maternity services have seen an increase in the incidence of poor mental health. A previous call to action [13] asserted that now is the time to prioritise women's mental health in the public health and mental health communities. 
Our aims in this study were therefore twofold: (1) To summarise the published perinatal mental health research conducted in the UK since the beginning of the COVID-19 pandemic and (2) to report on five NHS Trusts' responses to delivering perinatal mental health care over the past year.

\section{Materials and Methods}

The work conducted as part of this article was carried out using a twofold methodology: a rapid response critical review of the perinatal mental health literature published about COVID-19 and a knowledge mapping exercise documenting the perinatal mental health service provision and reconfiguration across five NHS Trusts during the COVID19 pandemic.

\subsection{Rapid Critical Review of the Literature}

The first part of this work presents a rapid response critical review of the literature published on perinatal mental health and COVID-19 early on during the pandemic. Critical reviews are used purposefully to synthesise materials after extensive, but not systematic, literature searching. In doing so, critical reviews provide a broad and informed narrative around an issue worthy of discussion by drawing upon specific literature for their specific contribution to the field of study (Grant and Booth, 2009). The critical review does therefore not assess for or evaluate quality, deeming all literature to contribute to the scoped knowledge base, regardless of its credibility or merit. A critical review, therefore, "typically manifest in a hypothesis or a model, not an answer" [14]; p. 93), more often rendering the outcome littered with more questions or new ways of thinking than when the review was first started. Within the context of this article, we present literature regarding the provision of perinatal mental health care during the COVID-19 pandemic and the effect of the pandemic on perinatal mental health. As a group, we searched individually for articles using literature databases and social media to gather publications related to the impact of COVID-19 on pregnant women and people from March 2020 up until May 2021. We searched for articles related to pregnancy, birth, the postnatal period, and COVID-19 from all over the world, with a focus on evidence arising from the UK. We did not discriminate on the basis of country of origin, type of article (e.g., empirical, review, theoretical), where it had been published, or supposed quality - all in-keeping with the guidelines for critical reviews, as explained above. We extracted any findings related to the impact of restrictions and the virus itself on the maternal mental wellbeing and service access satisfaction. We then met to review the papers as a group, inductively and iteratively sorting the 'headline information' from each paper into broad categories, which were then broadly synthesised before being reduced into two themes.

\subsection{Local Knowledge Mapping Exercise}

The second part of this work presents a knowledge mapping exercise, documenting responses to the pandemic (regarding perinatal mental health provision by midwives) by five NHS Trusts in London or counties bordering London in the United Kingdom. This knowledge mapping exercise draws on Trust-level policy regarding service provision and reconfiguration during the pandemic. The process of knowledge mapping has been described as proffering a mode of associating information from numerous sources with the aim of understanding the "dynamics at play in a health system or area of work" ([15]; p. 636). Knowledge mapping exercises are underpinned by the key principles of being "inclusive to ensure identification of all relevant evidence" ([16]; p. 3) whilst enabling a comparable and translatable snapshot of data [15]. The process can be broken down into five stages of data handling (as seen in Figure 1). It began with 'Data Acquisition', where we reported on the pandemic-related service reconfiguration by perinatal mental health midwives based in five Trusts in and around London, the United Kingdom. The second stage involved 'Data Refinement', where distinct thematic areas to include were agreed upon. These were: 'Retention of Existing Service Provision'; 'Reconfiguration of Service Provision'; 'Additional 
Provision to Support Staff'. After this, we engaged with the process of 'Data Pooling', whereby data sourced from all five NHS Trusts were recorded in their original format. Next came 'Data Comparison', where data were further refined to allow for uniform reporting, after which comparisons across the dataset could be made with explainers presented, as necessary, to illustrate Trust to Trust differences. The final process entailed 'Data Visualisation', where the uniform data and comparisons allowed for a final version of the knowledge mapping exercise to be presented in a tabular format. By doing this, we are able to descriptively report NHS Trust-level responses for the provision of perinatal mental health care by midwives between March 2020 and May 2021 - the first, second, and third waves of the COVID-19 pandemic in the UK. Whilst we have made every effort to ensure the accuracy of the information mapped at the time of writing this article, the changing nature of the pandemic means that local, national, and international guidance is changing rapidly; therefore, our knowledge mapping exercise provides a snapshot in time rather than a dynamic and all-encompassing report.

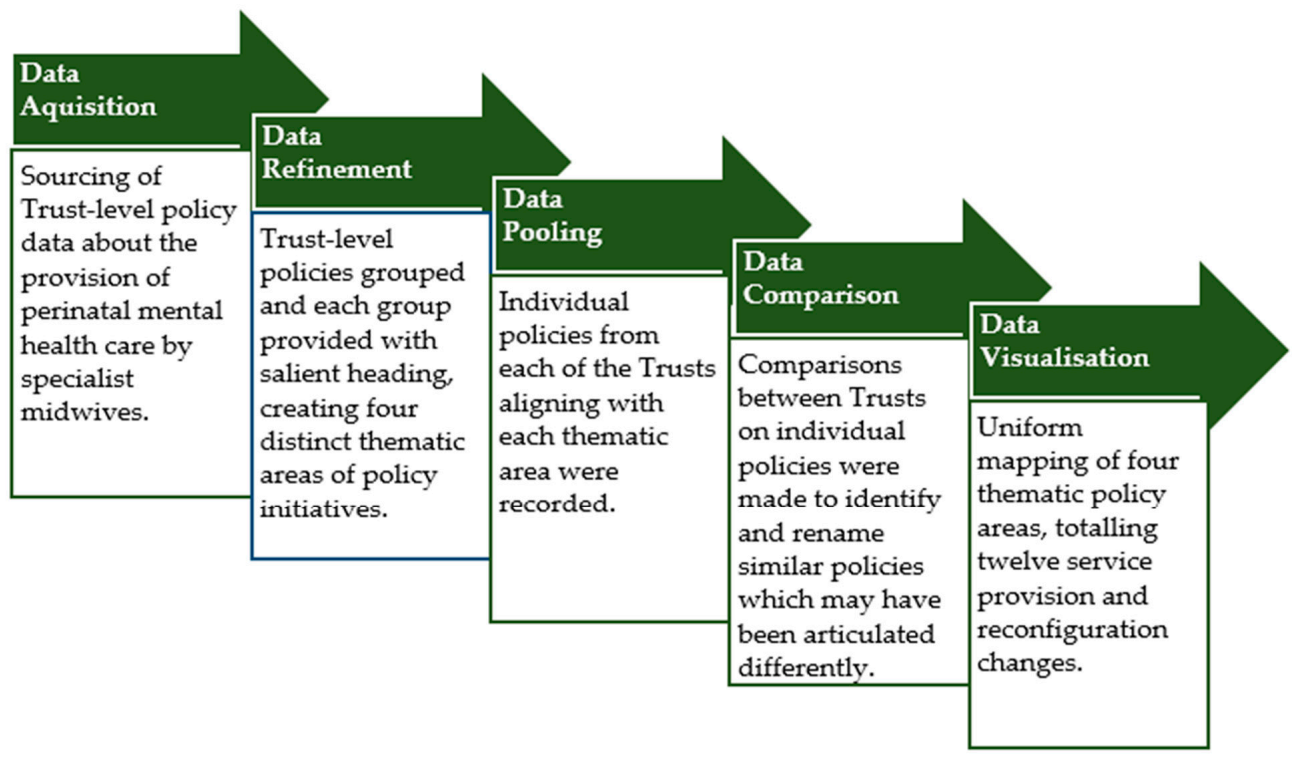

Figure 1. Knowledge mapping exercise process (adapted from Ebener et al., 2006) [15].

\section{Results}

The results of this work are reported in two halves. The first is dedicated to the rapid response critical review of the literature surrounding perinatal mental health care and care provision by perinatal mental health midwives during the COVID-19 pandemic, while the second reports on the findings from a knowledge mapping exercise of the provision and reconfiguration of perinatal mental health care services in five NHS Trusts during the COVID-19 pandemic.

\subsection{Rapid Response to COVID-19 Pandemic Critical Review of the Literature}

The following section describes the results of the rapid critical review, discussed as two themes: 'Increased Perinatal Distress' and 'Inaccessible Services and Support'.

\subsubsection{Increased Perinatal Distress}

Used as an umbrella term, perinatal distress describes symptoms of "depression, anxiety and stress which women may experience from conception to one year following birth". The genesis of perinatal distress can be varied and multifactorial, including physical, psychological, and socio-cultural factors. Women at particular risk may have a history of mental ill health; a history of abuse or domestic violence; or may have a limited support network, which includes financial or other major life stresses [17] 
The impact of the virus on pregnant women has caused an understandable intensity of distress. The initial lack of information surrounding the virus, the restrictions to social interactions, increased loneliness, women's concerns over their own health and fear of infection and transmission of the virus to their unborn child, on top of the sudden alterations in maternity care, all will have resulted in this [18]. Perinatal distress has been seen across the globe during the pandemic in high-, middle- and low-income countries alike ([19-21]). Tommy's charity conducted a survey of 1000 new or expectant mothers in the UK during the pandemic [22]. The charity found that $70 \%$ of women felt overwhelmed at some point in their pregnancy, with 14\% saying they struggled throughout, $49 \%$ feeling nervous or anxious, and $77 \%$ saying the pandemic had added to their fears.

A similar story was heard from the Babies in Lockdown report published by Best Beginnings [23]. A total of $87 \%$ of parents reported an increase in anxiety during the pandemic, and one of the compounding factors was the false information and advice given to pregnant women. The fear of infection, financial insecurity, social isolation, and the restrictions put on the partners and families of women/birthing people during antenatal and intrapartum care all added to reports of anxiety, confusion, and loss. The report found that $32 \%$ of families wanted help with their mental wellbeing. Those who had the highest levels of anxiety in relation to the pandemic were Black/Black British (46\%), Asian/Asian British (50\%), parents under 25 (54\%), and parents with household incomes of less than £16k (55\%).

Similar findings have been reported worldwide through a systematic review looking at the impact of COVID-19 on mental health in pregnancy from Canada, China, Italy, Turkey and Greece [24]. The review stated that there was a statistically significant increase in levels of anxiety compared to those of depression. A thematic analysis completed in Australia looking at a popular online forum for new and expecting parents found that this heightened level of distress was significant [20]. Women were worried about attending scans or going food shopping, with one woman stating, "I feel the most anxious, overwhelmed, isolated, out of control as I've ever felt before."

From pregnancy to two years postpartum is a crucial period of rapid development that sets the foundations for later health, happiness, and wellbeing [25]. It is a stage of exceptional vulnerability, when babies are especially reliant on their caregivers and very sensitive to their environment. Feedback from parents from the Babies in Lockdown report [23] stated that $25 \%$ of parents reported concerns about their relationship with their baby, and 35\% of these parents felt they would like to obtain help with this. In the recent report Working for Babies [25], professionals working with families were asked about the impact of the pandemic on mental health, with $98 \%$ saying that babies had been impacted by parental anxiety/stress/depression, leading to an effect on bonding and responsive care.

\subsubsection{Inaccessible Services and Support}

All of the reports relating to perinatal distress referenced the inability to access services or support. An international cross-sectional survey of 6894 participants in 64 different countries was conducted between 26 May 2020 and 13 June 2020 [26]. The most frequently described anxieties were related to pregnancy and birth, including family being unable to visit after birth (59\%), the lack of a support person during labour (55\%), and COVID-19 causing changes to their birth plan (41\%). Further concerns were related to not having access to medical appointments, which is associated with a significantly higher chance of posttraumatic stress and anxiety. This was recognised pre-pandemic through a systematic review and meta-synthesis for perinatal mental health services citing such barriers as lack of resources and the fragmentation of services [27], which now faced further restrictions due to staff self-isolating and a lack of face-to-face services.

A survey conducted in the UK found that almost half of all patients seen by a specialist mental health midwife reported their support to have stopped due to pandemic [28]. This was more frequently seen by first-time mothers, with one reporting, 'It's hard to feel like you're important, really just feel like we're inconveniencing the hospital' ([28]; p. 13). Further discussion 
showed the impact when these services were not available or taken away, "'devastated. Frightened. Powerless. Helpless. Shocked. I was having an elective c-section due to previous birth trauma. To have my support taken away 2 days before I went into theatre and be told I had to do it alone feels like it is the hardest thing I have ever been asked to do."' ([28]; p. 3).

The Best Beginnings [23] survey of women in the UK highlighted a lack of face-to-face appointments. "My anxiety is through the roof and I am trying to get professional help with it to manage, but I've been told there is a long waiting list." Only 32\% of those surveyed were confident that they could find mental health support if they needed it.

Perinatal mental health teams faced similar challenges, with the majority of service delivery needing to be delivered online $([29,30])$; however, the importance of face-to-face assessment in high-risk circumstances was emphasised by the rapid report into maternal deaths in the UK during the first three months of the pandemic, which included four suicides and two domestic homicides [31].

A study featured in the British Medical Journal [32] found that there was a notable increase in some Trusts restricting access for women requesting elective caesarean sections (ELCS) for non-medical reasons during the COVID-19 pandemic. This is concerning when considering the experiences many women have endured which have led them to this decision. Most women with secondary tokophobia requesting an ELCS will have a history of trauma during birth, and those women with primary tokophobia could have suffered a history of sexual trauma [33]. The potential impact on a woman's mental health if she is denied the opportunity to birth how she chooses is significant and the denial of this choice could not only cause further trauma but may also have long-term impacts on a woman's mental health.

In a survey by Tommy's [22], the majority of women reported hearing false information and misconceptions regarding pregnancy and birth. It is also important to consider that many women have requested ELCS during the pandemic as a result of fear of their partner not being at the birth due to visiting restrictions and increased anxiety surrounding childbirth. With virtual appointments being put in place in order to reduce the risk of pregnant women being exposed to COVID-19 during antenatal appointments, it could be said that women have had fewer opportunities to discuss their fears regarding birth, whilst the reduced continuity of carer could have impacted on women's ability to feel comfortable with being honest about their anxieties.

Lockdown measures have also meant that women and birthing people needed to remain inside for long periods of time, and this sadly saw an increase in domestic violence [21]. Midwives who would usually be able to see women face to face from as early as 6 weeks were now not seeing women in clinics until 28 weeks into their pregnancy. This reduced their ability to safely enquire about domestic violence and offer support in a timely manner. The rise in domestic violence calls for support from police to helplines rose worldwide [34]).

Working women have faced unfair treatment in the workplace during the pandemic. Pregnant Then Screwed [35] conducted an online survey of 19,950 mothers and pregnant women from 16 to 18 July 2020. The data showed that $15 \%$ of mothers either had been made redundant or expected to be made redundant and, of those, $46 \%$ said that a lack of childcare provision played a role in their redundancy. Worse still, the survey found that $45 \%$ of pregnant workers who were working outside of the home had not had an individual risk assessment conducted, rising to $52 \%$ for Black, Asian, and Ethnically Diverse pregnant women, who we know are at increased risk of severe COVID-19 illness [36]. All of this has impacted their ability to access services, with women not only being concerned about losing their job, but also being at greater risk of infection if they were having to travel using public transport and then being made to sit in waiting rooms before their scheduled antenatal appointments. 


\subsection{Knowledge Mapping Exercise}

The section which follows reports the results of the local knowledge mapping exercise, detailing the perinatal mental health provision by Specialist Midwives at five NHS Trusts in response to COVID-19. Findings are presented under four distinct themes: 'Retention of Existing Service Provision'; 'Additional Services Provided'; 'Reconfiguration of Service Provision'; 'Additional Provision to Support Staff Wellbeing'. These are explained simplistically in Table 1 and narratively in the prose below.

\subsubsection{Retention of Existing Service Provision}

Retention of existing services extended to the assurance of face-to-face appointments being offered to all from the beginning of pregnancy to discharge from maternity care, if that is what women wanted. Further, perinatal mental health midwives continued to work alongside caseloading midwives, where caseloading models of care were retained. It should be noted, however, that every Trust involved in this paper saw caseload/continuity of carer teams disbanded and/or used to cover areas with poor staffing levels. Caseload teams differ to traditional midwifery care in that they offer a one-to-one continuity of care throughout pregnancy and birth.

\subsubsection{Additional Services Provided}

During the pandemic, it was noticed there was a marked increase in the need for ad hoc support for women suffering with anxiety at all Trusts. At Trust A, this rose by $62 \%$, while it rose by $40 \%$ at Trust C. All midwives contributing to this knowledge mapping exercise increased their availability either through increased hours, staffing, or ad hoc support.

There was also a noted increase in requests for elective caesarean sections (ELCS). Trust B responded to this surge through the specialist midwife for mental health offering a 'Birth Without Fear' class. This was intended to enable women whose anxiety was influencing their decisions around birth to have access to specialist mental health support and evidence-based information, ensuring they were able to make an informed choice about their birth.

The Pan-London Perinatal Mental Health Midwifery Forum developed a resource we could share with women and staff that gave information about COVID-19, seeking mental ill health support, resources to share with children, online support groups, and online exercise classes for pregnant women and staff.

\subsubsection{Reconfiguration of Service Provision}

All specialist perinatal mental health midwives involved in this paper adapted their services to allow for further ad hoc support as needed with the increased levels of anxiety. This included adapting existing provision to either partial or fully online provision to counter any concerns about exposure to infection from having to come into the hospital. This not only led to an anecdotal reduction in levels of anxiety but also enabled patients to inquire safely about domestic violence and signposted them to services early on.

\subsubsection{Additional Provision to Support Staff Wellbeing}

Each Trust was supportive in some way, with in-house support aimed at maintaining and improving staff wellbeing. This varied from relaxation rooms to links for online support and to more specialist services. Trust E went one step further. The local Parent-Infant Psychotherapy (PIP) service together with a perinatal psychologist also worked with the perinatal mental health midwife to set up a service to support all maternity staff at the height of the first wave of the pandemic. The project was aimed at giving maternity staff the opportunity to contact a member of the PIP team by e-mail or phone if they wanted to seek advice or support following their shift if they felt they had particularly challenging cases. This was not a referral service for patients, but more a service to give staff the opportunity to reflect and debrief with a trained professional. 
Table 1. Reconfiguration of perinatal mental health service provision by trust.

\begin{tabular}{|c|c|c|c|c|c|c|}
\hline Theme & $\begin{array}{l}\text { Service Provisions and } \\
\text { Reconfigurations }\end{array}$ & Trust A & Trust B & Trust C & Trust D & Trust E \\
\hline \multirow{2}{*}{ 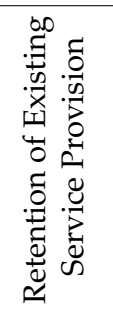 } & $\begin{array}{l}\text { Continuation of face-to-face } \\
\text { appointments for women with a } \\
\text { current diagnosis of mental illness }\end{array}$ & $\checkmark$ & $\checkmark$ & $\checkmark$ & $\checkmark$ & $\checkmark$ \\
\hline & $\begin{array}{c}\text { Perinatal Mental Health Midwives } \\
\text { working alongside Caseloading } \\
\text { Midwives }\end{array}$ & $\checkmark$ & $\checkmark$ & $\checkmark$ & $\checkmark$ & $x$ \\
\hline \multirow{4}{*}{ 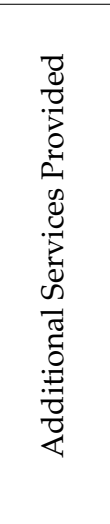 } & $\begin{array}{l}\text { Additional support provided (to } \\
\text { meet increased reporting of } \\
\text { perinatal anxiety) }\end{array}$ & $\checkmark$ & $\vee$ & $\vee$ & $\checkmark$ & $\checkmark$ \\
\hline & $\begin{array}{l}\text { Provision of co-developed } \\
\text { resource offering virtual support } \\
\text { for women and/or families }\end{array}$ & $\checkmark$ & $\vee$ & $\checkmark$ & $\checkmark$ & $\checkmark$ \\
\hline & $\begin{array}{l}\text { Provision of 'Birth Without Fear' } \\
\text { class to meet rise in elective } \\
\text { caesarean section requests }\end{array}$ & $x$ & $\checkmark$ & $x$ & $x$ & $x$ \\
\hline & $\begin{array}{l}\text { Increased Perinatal Mental Health } \\
\text { Midwife staffing to meet demand } \\
\text { on service }\end{array}$ & $x$ & $x$ & $x$ & $x$ & $\checkmark$ \\
\hline \multirow{5}{*}{ 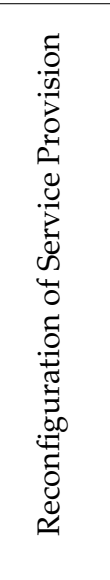 } & $\begin{array}{l}\text { Face-to-face exercise classes } \\
\text { moved to on-line provision }\end{array}$ & $\checkmark$ & $\theta$ & $\theta$ & $\theta$ & $\theta$ \\
\hline & $\begin{array}{l}\text { Art psychotherapy moved to } \\
\text { online provision }\end{array}$ & $\checkmark$ & $\theta$ & $Q$ & $\theta$ & $\theta$ \\
\hline & $\begin{array}{l}\text { Virtual antenatal clinics offering } \\
\text { continuity of (midwife) carer }\end{array}$ & $x$ & $\vee$ & $x$ & $x$ & $x$ \\
\hline & $\begin{array}{l}\text { Provision of support for } \\
\text { partner/parent to accompany } \\
\text { woman/birthing person in } \\
\text { exceptional circumstances only }\end{array}$ & $\checkmark$ & $\checkmark$ & $\checkmark$ & $\checkmark$ & $\checkmark$ \\
\hline & $\begin{array}{l}\text { Provision of virtual appointments } \\
\text { for those unable or not wanting to } \\
\text { attend face-to-face }\end{array}$ & $\vee$ & $\vee$ & $\checkmark$ & $\vee$ & $\checkmark$ \\
\hline 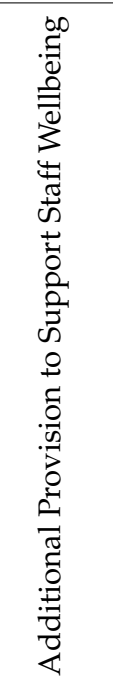 & $\begin{array}{l}\text { In-house support for staff mental } \\
\text { wellbeing }\end{array}$ & $\vee$ & $\vee$ & $\vee$ & $\vee$ & $\vee$ \\
\hline
\end{tabular}

Key: $\checkmark$ = yes: continuation of service provision; applicable.
= yes: addition of service provision; $x=$ no; $Q=$ not 
The Pan-London Perinatal Mental Health Midwives Forum also adapted in light of what was happening with COVID-19. Previously meeting every three months and face to face, we changed this to be a virtual monthly drop-in. This opportunity to check in on one another and share what each service was doing was hugely influential in the changes we could then implement within our own Trusts.

\section{Discussion}

\subsection{Summary of Main Findings}

The COVID-19 pandemic has caused an unprecedented health system shock which has required the significant reconfiguration of the health service in order to continue to provide healthcare whilst also reducing the risk of viral transmission. For maternity care, guidance has been produced consistently by the RCOG with regard to how best to provide maternity care and updating advice on the risk posed by the virus to pregnant and postpartum women [37]. Maternity services have therefore been subject to repeated service-level reconfiguration [8], rendering many women unhappy with the care they received [38]. Specifically, it has been reported that women (in the general population) in the UK have experienced some of the highest levels of perinatal mental ill health ever recorded empirically $[39,40]$ and were adversely affected by restrictions associated with COVID-19 [41,42], especially with regard to missing out on social and healthcare professional support [43].

Women and birthing people have faced unparalleled change at a time in their life which should usually allow for preparation for parenthood. This preparatory work in the lead up to the transition into parenthood should normally be accomplished with the support of healthcare professionals, including a midwife and health visitor. For women with mental ill health, this should be further supported by a specialist perinatal mental health midwife [12]. Despite numerous publications [37,44,45] recommending the continuity of care(r) and services, COVID-19 disrupted this support for many families, who were left to navigate their maternity care through a screen on their laptop and/or birth alone amongst strangers. This mapping exercise showed that the work the perinatal mental health midwives were able to adapt allowed for care to continue in as normal a way as possible, thus combatting the issues arising in perinatal mental health due to COVID-19 (which were identified in the critical review). This was only due to ongoing communication and support from management, the personal and individual drive from the perinatal mental health midwives themselves, and the peer support between members of the PanLondon Perinatal Mental Health Midwife Forum. Future and ongoing planning needs to include the ability to co-produce resources, to communicate with women and families, and for specialist midwives to remain in place to ensure that perinatal mental health care is delivered efficaciously and with the compassion it requires.

\subsection{Strengths, Limitations, and Future Directions}

To our knowledge, this is the first paper to document how services in the United Kingdom (NHS Trusts) adapted their perinatal mental health care provision, as offered by specialist perinatal mental midwives, for women and birthing people. However, we realise that this knowledge mapping exercise was limited to five predominantly London-based NHS Trusts and therefore may not be broadly or directly applicable to perinatal mental health services in other regions or countries. Another limitation linked to this one is the fact we that were unable to provide individual Trust-level statistics due to the potential for identifiability. This is the nature of local projects, and future research could rectify this using national survey methodologies, as have previously been used [8]. Future work should include a wider spectrum of Trusts throughout the UK and a wider global mapping of perinatal mental health services to see where services continued and/or adaptations were successful and ultimately share learning and best practices.

Combined with this knowledge mapping, we also offer a rapid critical review of the literature published in the early stages of the pandemic and broadly synthesise the landscape of perinatal mental health and how it was affected by the onset of COVID- 
19. Whilst we provide a rapid review of the work published, the pandemic has led to many empirical explorations of maternal and child health, care, and service provision. Consequently, further systematic reviews with specific questions are required to provide a more thorough insight into the effects of the pandemic on perinatal mental health services and care provision.

\subsection{Conclusions}

The impact of the COVID-19 pandemic is still not fully understood, but, as seen within services in London and based on articles from papers published early in the pandemic, increased levels of perinatal distress and restrictions to perinatal mental health services have been witnessed globally. Ongoing and global evaluations of service configurations similar to ours will be helpful as we move from the pandemic into post-pandemic recovery, building better services in what has been dubbed the "new normal". In doing so, we attempt to do our utmost to protect our future populations through shared learning, best practice, and adaptations in the way we provide care.

Author Contributions: Conceptualisation, L.B. and L.W.; methodology, S.A.S.; software, L.B.; validation, S.A.S. and A.E.; formal analysis, L.B. and S.A.S.; investigation, L.B., L.W., T.v.d.V., O.A., S.H., E.F.; resources, L.B.; data curation, L.B. and S.A.S.; writing-original draft preparation, L.B.; writing-review and editing, S.A.S. and A.E.; visualisation, S.A.S. and L.B.; supervision, S.A.S.; project administration, L.B. All authors have read and agreed to the published version of the manuscript.

Funding: This research received no external funding. The APC was waived by the journal.

Institutional Review Board Statement: Not applicable due to the nature of this article.

Informed Consent Statement: Not applicable.

Data Availability Statement: Not applicable.

Acknowledgments: S.A.S and A.E. are currently supported by the National Institute for Health Research Applied Research Collaboration South London (NIHR ARC South London) at King's College Hospital NHS Foundation Trust. The views expressed are those of the authors and not necessarily those of the NIHR or the Department of Health and Social Care.

Conflicts of Interest: The authors declare no conflict of interest.

\section{References}

1. Khan, L. Falling through the Gaps: Perinatal Mental Health and General Practice; Centre for Mental Health: London, UK, 2015; Available online: https:/ / www.centreformentalhealth.org.uk/publications/falling-through-gaps (accessed on 15 July 2021).

2. Papworth, R.; Harris, A.; Durcan, G.; Wilton, J.; Sinclair, C. Maternal Mental Health during a Pandemic: A Rapid Evidence Review of Covid-19's Impact. 2021. Available online: https:/ / www.centreformentalhealth.org.uk/publications/maternal-mental-healthduring-pandemic (accessed on 3 November 2021).

3. Watson, H.; Harrop, D.; Walton, E.; Young, A.; Soltani, H. A systematic review of ethnic minority women's experiences of perinatal mental health conditions and services in Europe. PLoS ONE 2019, 14, e210587. [CrossRef] [PubMed]

4. Howard, L.; Ryan, E.; Trevillion, K.; Anderson, F.; Bick, D.; Bye, A.; Byford, S.; O'Connor, S.; Sands, P.; Demilew, J.; et al. Accuracy of the Whooley questions and the EPDS in identifying depression and other mental disorders in early pregnancy. Br. J. Psychiatr. 2018, 212, 50-56. [CrossRef] [PubMed]

5. Howard, L.M.; Khalifeh, H. Perinatal mental health: A review of progress and challenges. World Psychiatry 2020, $19,313-327$. [CrossRef] [PubMed]

6. Brooks, S.K.; Webster, R.K.; Smith, L.E.; Woodland, L.; Wessely, S.; Greenberg, N.; Rubin, G.J. The psychological impact of quarantine and how to reduce it: Rapid review of the evidence. Lancet 2020, 395, 912-920. [CrossRef]

7. Psychiatry, T.L. Isolation and inclusion. Lancet Psychiatr. 2020, 5, 371. [CrossRef]

8. Jardine, J.; Relph, S.; Magee, L.A.; von Dadelszen, P.; Morris, E.; Ross-Davie, M.; Draycott, T.; Khalil, A. Maternity services in the UK during the coronavirus disease 2019 Pandemic: A national survey of modifications to standard care. BJOG: Int. J. Obstet. Gynaecol. 2021, 128, 880-889. [CrossRef]

9. Royal College of Midwives and Royal College of Obstetricians and Gynaecologists. Coronavirus (COVID-19) and Pregnancy. 2021. Available online: https://www.rcog.org.uk/coronavirus-pregnancy (accessed on 1 November 2021).

10. Adhanom Ghebreyesus, T. Addressing mental health needs: An integral part of COVID-19 response. World Psychiatr. 2020, 19, 129-130. [CrossRef] 
11. Matvienko-Sikar, K.; Meedya, S.; Ravaldi, C. Perinatal mental health during the COVID-19 pandemic. Women Birth 2020, 33, 309-310. [CrossRef]

12. Midwives, Royal College of London. Specialist Mental Health Midwives: Why They Matter; Royal College of Midwives: London, UK, 2018.

13. Silverio, S.A. Women's mental health a public health priority: A call for action. J. Public Ment. Health 2020, 20, 60-68. [CrossRef]

14. Grant, M.J.; Booth, A. A typology of reviews: An analysis of 14 review types and associated methodologies. Health Inf. Libr. J. 2009, 26, 91-108. [CrossRef]

15. Ebener, S.; Khan, A.; Shademani, R.; Compernolle, L.; Beltran, M.; Lansang, M.A.; Lippman, M. Knowledge mapping as a technique to support knowledge translation. Bull. World Health Organ. 2006, 84, 636-642. [CrossRef]

16. Pilkington, G.; Knighting, K.; Bray, L. The specification, acceptability and effectiveness of respite care and short breaks for young adults with complex healthcare needs: Protocol for a mixed-methods systematic review. BMJ Open 2019, 9, e030470. [CrossRef] [PubMed]

17. Zapata-Delgado, A.; Perinatal Distress: Early Screening and Management. PHN Central and Eastern Sydney. 2021. Available online: https:/ / www.cesphn.org.au/news/latest-updates/57-enews/2425-perinatal-distress-early-screening-and-management (accessed on 1 November 2021).

18. Motrico, E.; Mateus, V.; Bina, R.; Felice, E.; Bramante, A.; Kalcev, G. Good practices in perinatal mental health during the COVID-19 pandemic: A report from task-force RISEUP-PPD COVID-19. Clínica Salud. 2020, 31, 155-160. [CrossRef]

19. Brown, S. Perinatal mental health and the COVID-19 pandemic. World Psychiatr. 2020, 19, 333-334. [CrossRef]

20. Chivers, B.; Garad, R.; Boyle, J.; Skouteris, H.; Teede, H.; Harrison, C. Perinatal Distress during COVID-19: Thematic Analysis of an Online Parenting Forum. J. Med. Internet. Res. 2021, 22, e22002. [CrossRef] [PubMed]

21. Kotlar, B.; Gerson, E.; Petrillo, S.; Langer, A.; Tiemeier, H. The impact of the COVID-19 pandemic on maternal and perinatal health: A scoping review. Reprod. Health, 18, 1-39.

22. The Guardian. Most New and Expectant Mothers Feel More Anxious Due to Covid, Finds Survey. 2021. Available online: https://www.theguardian.com/uk-news/2021/jan/01/most-new-and-expectant-mothers-feel-more-anxious-due-tocovid-finds-surve (accessed on 1 November 2021).

23. Best Beginnings, Home-Start UK, Parent-Infant Foundation. Babies in Lockdown: Listening to Parents to Build Back Better; ParentInfant Foundation: London, UK, 2020.

24. Hessami, K.; Romanelli, C.; Chiurazzi, M.; Cozzolino, M. COVID-19 pandemic and maternal mental health: A systematic review and meta-analysis. J. Matern-Fetal Neonatal Med. 2020, 21, 845. [CrossRef]

25. Reed, J.; Parish, N.; Working for Babies. Lockdown Lessons from Local Systems. First 1001 Days Movement. 2021. Available online: https:/ / parentinfantfoundation.org.uk/wp-content/uploads/2021/01/210121-F1001D_Working_for_Babies_v1.2 -FINAL-compressed_2.pdf (accessed on 1 November 2021).

26. Basu, A.; Kim, H.H.; Basaldua, R.; Choi, K.W.; Charron, L.; Kelsall, N. A cross-national study of factors associated with women's perinatal mental health and wellbeing during the COVID-19 pandemic. PLoS ONE 2021, 16, e0249780. [CrossRef] [PubMed]

27. Sambrook Smith, M.; Lawrence, V.; Sadler, E.; Easter, A. Barriers to accessing mental health services for women with perinatal mental illness: Systematic review and meta-synthesis of qualitative studies in the UK. BMJ Open 2019, 9, e024803. [CrossRef]

28. Baptie, G.; Baddelley, A.; Smith, J. The Impact of COVID-19 on Women's Maternity Choices. 2021. Available online: https: / / drive.google.com/file/d/1UyzRKrQHvxhRcTIRA8mhy8CyJ7FV_PNU/view (accessed on 3 November 2021).

29. Holmes, E.A.; O'Connor, R.C.; Perry, V.H.; Tracey, I.; Wessely, S.; Arseneault, L.; Ballard, C.; Christensen, H.; Silver, R.C.; Everall, I.; et al. Multidisciplinary research priorities for the COVID-19 pandemic: A call for action for mental health science. Lancet Psychiatr. 2020, 41, 547-560. [CrossRef]

30. Wilson, C.; Dalton-Locke, C.; Johnson, S.; Simpson, A.; Oram, S.; Howard, L. Challenges and opportunities of the COVID-19 pandemic for perinatal mental health care: A mixed methods study of mental health care staff. Arch. Women's Ment. Health. 2020, 24, 749-757. [CrossRef]

31. Knight, M.; Bunch, K.; Cairns, A.; Cantwell, R.; Cox, P.; Kenyon, S.; Kotnis, R.; Luca, N.; Lucas, S.; Marshall, L.; et al. Saving Lives, Improving Mothers' Care Rapid Report: Learning from SARS-CoV2-Related and Associated Maternal Deaths in the UK March-May 2020; Healthcare Quality Improvement Partnership and National Perinatal Epidemiology Unit, University of Oxford: Oxford, UK, 2020.

32. Romanis, E.C.; Nelson, A. Homebirthing in the United Kingdom during COVID-19. Med. Law Int. 2020, 20, 183-200. [CrossRef]

33. Heimstad, R.; Dahloe, R.; Laache, I.; Skogvoll, E.; Schei, B. Fear of childbirth and history of abuse: Implications for pregnancy and delivery. Acta Obstet. Gynecol. Scand. 2006, 85, 435-440. [CrossRef] [PubMed]

34. Graham-Harrison, E.; Giuffrida, A.; Smith, H.; Ford, L. Lockdowns around the World Bring Rise in Domestic Violence. 2020. Available online: https://www.theguardian.com/society/2020/mar/28/lockdowns-world-rise-domestic-violence (accessed on 3 November 2021).

35. Childcare, Covid and Career: The True Scale of the Crisis Facing Working Mums. 2020. Available online: https: / / pregnantthenscrewed.com/the-covidcrisis-effect-on-working-mums / (accessed on 3 November 2021).

36. Knight, M.; Bunch, K.; Cairns, A.; Cantwell, R.; Cox, P.; Kenyon, S.; Kotnis, R.; Lucas, D.N.; Lucas, S.; Nelson-Piercy, C.; et al. Saving Lives, Improving Mothers' Care Rapid Report 2021: Learning from SARS-CoV-2-Related and Associated Maternal Deaths in the UK June 2020-March 2021; National Perinatal Epidemiology Unit, University of Oxford: Oxford, UK, 2021. 
37. Royal College of Midwives; Royal College of Obstetricians and Gynaecologists. Coronavirus (COVID-19) Infection in Pregnancy: Information for Healthcare Professionals. 2021. Available online: https:/ /www.rcog.org.uk/en/guidelines-research-services / coronavirus-covid-19-pregnancy-and-womenshealth/ (accessed on 3 November 2021).

38. Silverio, S.A.; De Backer, K.; Easter, A.; von Dadelszen, P.; Magee, L.A.; Sandall, J. Women's experiences of maternity service reconfiguration during the COVID-19 pandemic: A qualitative investigation. Midwifery 2021, 102, 103116. [CrossRef] [PubMed]

39. Fallon, V.; Davies, S.M.; Silverio, S.A.; Jackson, L.; De Pascalis, L.; Harrold, J.A. Psychosocial experiences of postnatal women during the COVID-19 pandemic. A UK-wide study of prevalence rates and risk factors for clinically relevant depression and anxiety. J. Psychiatr. Res. 2021, 136, 157-166.

40. Silverio, S.A.; Davies, S.M.; Christiansen, P.; Aparicio-García, M.E.; Bramante, A.; Cheng, P.; Costas-Ramón, N.; de Weerth, C.; Della Vedova, A.M.; Infante Gil, L.; et al. A validation of the Postpartum Specific Anxiety Scale 12-item research short-form for use during global crises with five translations. BMC Pregnancy Childbirth 2021, 21, 1-12. [CrossRef]

41. Jackson, L.; De Pascalis, L.; Harrold, J.A.; Fallon, V.; Silverio, S.A. Postpartum women's psychological experiences during the COVID-19 pandemic: A modified recurrent cross-sectional thematic analysis. BMC Pregnancy Childbirth 2021, 21, 1-16. [CrossRef]

42. Silverio, S.A.; Easter, A.; Storey, C.; Jurković, D.; Sandall, J. Preliminary findings on the experiences of care for parents who suffered perinatal bereavement during the COVID-19 pandemic. BMC Pregnancy Childbirth 2021, 840, 1-13. [CrossRef]

43. Jackson, L.; De Pascalis, L.; Harrold, J.A.; Fallon, V.; Silverio, S.A. Postpartum women's experiences of social and healthcare professional support during the COVID-19 pandemic: A recurrent cross-sectional thematic analysis. Women Birth 2021, in press. [CrossRef]

44. England, N.H.S. Implementing Better Births: Continuity of Carer; NHS: London, UK, 2017.

45. Fernandez Turienzo, C.; Newburn, M.; Agyepong, A.; Buabeng, R.; Dignam, A.; Abe, C.; Bedward, L.; Rayment-Jones, H.; Silverio, S.A.; Easter, A.; et al. Addressing inequities in maternal health among women living in communities of social disadvantage and ethnic diversity. BMC Public Health 2021, 21, 1-5. [CrossRef] 